\title{
Research on the Washing Machine Design Improvement of Specific Consumption Groups
}

\author{
Meina Wang, a \\ ${ }^{1}$ Sichuan University Jinjiang College, Chengdu, Sichuan, China
}

\begin{abstract}
This research focuses on the "Improved Product R\&D Project" of Sichuan Chaochen Electric Co., Ltd, analyzing its market status from the life style of its main consumer groups, namely users of the secondary and tertiary markets. Through field observation and in-depth interview methods, the user's daily habits and demands for washing machines are closely looked into. Then the research comes up with some design elements aiming at the low-end markets, and also offers the corresponding specific design proposal. On this basis, it provides new ideas and fresh design methods for the appearance improvements of the secondary and tertiary market washing machines, from angels of external morphology, human-computer interaction and concept trends etc, thus in hopes of being referential to the actual product improvements of the mid-and-low-end washing machine markets.
\end{abstract}

\section{Introduction}

With the continuous improvement of people's living standards in the secondary and tertiary markets and the gradual saturation of the household appliance market in the first-tier cities, the household appliance companies would be focus on strategic layouts, because of the development of secondary and tertiary markets. For one thing, users in this market want household appliances to change their lives and improve their quality of life. For another thing, the lack of user-friendly household appliance designs leads to great frustration in their daily use. Therefore, the improvement of the household appliance designs in the secondary and tertiary markets , to make them more humane, is a manifestation of respect and concern for people of different living standards and levels.

\section{Research Background}

The survey has found out that there are significant differences in the living environment, economic conditions, education levels, and living habits between users in the mid-and-low-end markets and those in the first-tier cities, which leads to different aesthetic characteristics, perceptions, and preferences. However, currently, many household electrical appliance companies directly cut the price of those out-products from the firsttier cities and put them into these secondary and tertiary markets. This is an irresponsible approach that lacks humanistic care. The products needed in these markets should never simply be the "reduced version" but products that have core functions, in fit with the operating environment, well meet quality requirements, and are practical and cost-effective. Therefore, the improvement and optimization of household appliance product designs in the secondary and tertiary markets is imminent.

Although the Chinese washing machine market starts late, it has developed rapidly, and is currently at a mature stage. Being faced with an excess capacity and the gradual saturation in urban markets, many washing machine companies exploit the secondary and tertiary markets as their strategic goal. According to the National Information Center's statistic data, sales of major washing machine companies in these markets have increased significantly in recent years. For example, the sales of Haier washing machines in this market have maintained a growth rate of over $40 \%$ for three consecutive years; Little Swan enjoys a growth rate of up to $300 \%$, compared with last year; that of Sanyo Washing Machine increased by more than $80 \%$ year-on-yea; and sales of Panasonic Washing Machine in this market grow by $20 \%$. The explosive growth of secondary and tertiary market's washing machine sales allows the companies to notice the huge potential of this market. Meanwhile, Chinese Government's Consumer Electronics Subsidy Program (Home Appliances to the Countryside) is stimulating the release of consumer energy in the secondary and tertiary markets. The sinking of key enterprise's products and sales channels has also ensured the realization of this kind of consumer enthusiasm.

This research focuses on the "Improved Product R\&D Project" of Sichuan Chaochen Electric Co., Ltd, analyzing its market status from the life style of its main consumer groups, namely users of the secondary and tertiary markets. Through questionnaires, field visits and in-depth interview methods, the user's daily habits and demands for washing machines are closely looked into. It then comes up with some design elements aiming at the low-end markets, providing a reference for improved design and

\footnotetext{
${ }^{*}$ Corresponding author: Meina Wang ${ }^{\mathrm{a} E m a i l ~ A d d r e s s: ~ c i m o n a @, 126 . c o m ~}$
} 
new product development in those markets.

\section{Market Research Result Analysis}

In the early stage of market research, questionnaire was mainly adopted, by dividing the samples into 10 research groups and independently choosing consumers from residential areas, supermarkets and electronic stores, meanwhile ensuring the sample number of each group is $\geq 100$.

In addition with the sales data provided by the marketing department of Chaochen Company, the analysis of the survey results found out that in the secondary and tertiary cities, washing machines with large capacity is more popular. The first-time consumer as well as those households that owns multiple numbers of washing machines usually choose the ones of $4-6 \mathrm{~kg}$. And for the second-time buyers who need one for upgrading, the common option is a big capacity washing machine of $7-8 \mathrm{~kg}$ or above, as in Table 1.

Table 1. The Survey Results of the Washing Machine Capacity Choices

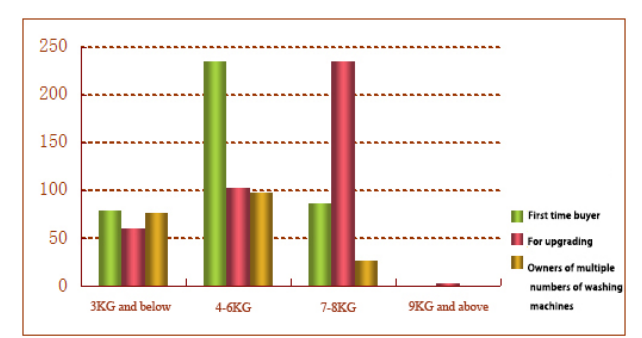

The survey of human-computer interaction interfaces reveals that users prefer touch screen operation interfaces. However, the touch screen interfaces are not always visualized. Along with the gradual increasement of washing machine functions, the most troublesome problem for the first time users is the lack of direct visual understanding of operational approach. Therefore, this design proposal attempts to design the operation interface as a soft interface - a touch-screen operation interface, focusing on improving the straightforwardness of the operation, enhancing the intelligence of the washing machine, and adopting the fuzzy processing of one simple touch as much as possible.

Besides, through field observation and user interviews, it is noticed that different positioning of the washing machines may sometimes leads to problems of moist or overlighting, and that some washing machines are too cumbersome to move or difficult to clean. Those find-outs have provided us with necessary information for our subsequent designs.

\section{Specific Research and Research Results}

After analyzing and summarizing the results of market research and research on people's life forms, we found that the following design elements can effectively guide this washing machine improved design practice.

\subsection{Starting from the human-computer interaction interface, simplify the interface and the button, highlighting humanization design.}

Low-end users usually cannot tolerate complicated operations. And the ease of use design should be visualized with easy-to-understand interface operation mode, realizing human-computer interaction to provide with a humanized design.
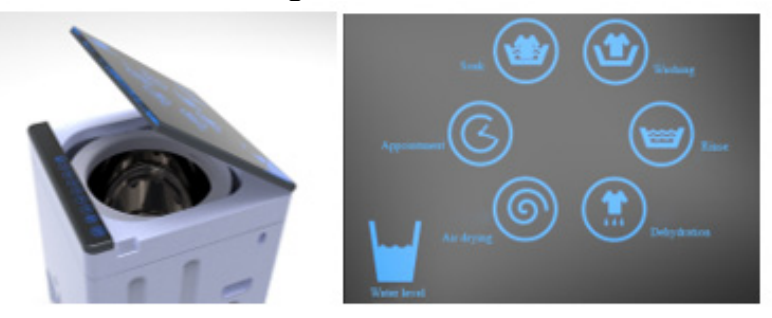

Figure 1. Human-machine interface of washing machines respectively under non-operating and working conditions

In this project design proposal, Plan One: "geometry" is to make innovative attempts on the interface and operation modes, as shown in Figure 1. This design makes full use of the oversized panel of a fully automatic washing machine, combined with current flat panel technology, to make the laundry process more joyful. At the same time, in design of the icon, the existing textbased format is abolished, being replaced by large icons with greater visibility, and one-click intelligent processing. In doing so, on the one hand, it facilitates visually impaired middle-aged and elderly people. On the other hand, it allows users to operate easily without instruction books, and is particularly suitable for consumer groups with low education levels in the middleand-low-end markets.

Although the low-end market has limited consumption capacity, still its consumers eager to enjoy the convenience brought by high technology. Along with the rapid development of science and technology, the technical costs have been reduced greatly. According to the company's R\&D (Research and Development) to production time cycle, for a product that would be put in market 3-5 years later, its design must fit into the future trend.

\subsection{Being of high quality and low cost, the appearance of traditional washing machines should be improved with its cost been well controlled.}

High-quality with low-cost is widely expected, especially by the low-end users. The designers found that with the stretching of lines and patches, the washing machine would appear more capaciousness without enlarging the inner cylinder. Such a tiny skill may increase the washing machine sales, while not causing any substantial increase in costs. This proposal has been unanimously approved by the Research and Development Department of Chaochen 


\section{Company.}

\subsubsection{Rejuvenate the traditional semi-automatic washing machine}

While the market has gradually been occupied by the automatic washing machines, the semi-automatic washing machines survive with their own unique features. Compared with fully automatic washing machines, semiautomatic double-cylinder washing machines, although cannot realize one-button operation function, need less water, and the three functions of washing, rinsing and dehydration can be freely selected according to needs, and the detergent can also be reduced if needed. Therefore, in the secondary and tertiary markets, there are still many consumers who choose semi-automatic twin-cylinder washing machines. In order to maintain its competitive advantage of low-cost and manual-selective capacity, this time's design will focus on the appearance improvement, and most prominently on the main cover.

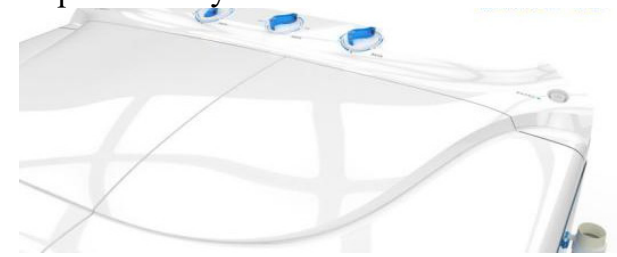

Figure 2. Overall plan of the "Yun" two-cylinder washing machine and its upper cover design details

Plan Two. The "Yun" washing machine chooses sea waves as its theme, having its upper cover been designed in curve, featuring the mobility of water, as in Figure 2. As for the operation area, integrated processing is performed, using level difference to segment each zone. Besides, innovation has been made on the button design, taking "wave" as its theme in modeling and texture. Thus, the washing machine seems more stylish, dispelling a sense of rigid simplification usually felt in low-end products. This represents humanistic care for the consumers' inner feeling. In addition, the smooth lines make the upper cover mellow and full, and it seems to be more solid, raising the customer's satisfaction while purchasing.

\subsubsection{Create visual illusion of a large capacity without really changing the inner diameter of the cylinder, having the cost of mould in control.}

Due to cost control restrictions, consumer preferences and the particularity of surroundings, automatic washing machines launched in the second and tertiary market are mostly pulsator type instead of roller ones. However, the space for mold shape improvement of the washing machine top cover is very limited. How to do the largecapacity designs for such products?

Mosaic gives people the feeling of delicacy and animation, with layers of rich colors. The integral treatment of the washing machine top cover may provide a sense of visual expansion. But the flat and monotonous design still gives customers bad user experiences. In such cases, the designer can make use of the active mosaic to add joy and avoid monotony, taking diverse mosaic display forms for different working modes. As shown in Figure 3.

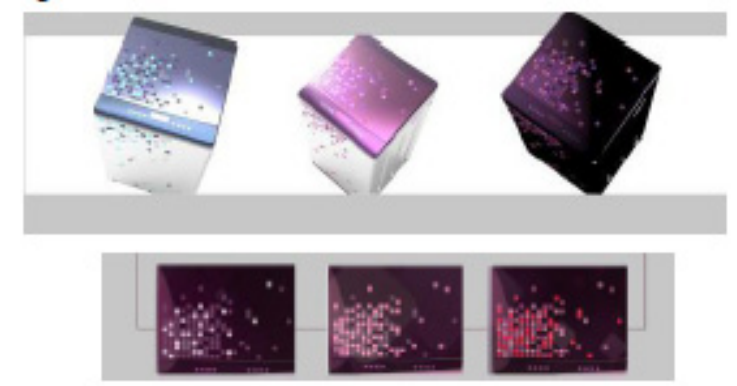

Figure 3. Use the mosaic display to add joy

Also, the designer may get rid of the conventional pulsator washing machine design of separating the console and the cover plate. After integration, hide the control button and the circuit under the large cover plate. Such treatment may give the consumers the impression of a large capacity, with high quality and low cost, thus enhance their purchasing desire. This design concept and tactic has been approved in the marketing department of Chaochen company.

\subsection{Conceptual Design Based on New Energy Technology}

Along with the intensification of traditional energy crisis and the prominent pollution problems, the future technology would inevitably highlight natural clean energy or new energy technologies. Thus the dynamic design of washing machines would certainly follow the trend. It is found through the market research that some consumers prefer to use washing machines in the open yard. There comes this program of conceptual design on the utilization of solar energy. Also, it offers some trend forecasting options for the company's future product development.

The design of this washing machine adopts a large surface, smooth overall lines and chrome-plate frame, featuring its simple and elegant style, besides offering a sense of science and technology. There are hidden handles on its side to preserve the washing machines' integrated appearance. General design is adopted for its shell, and there are multiple colors available for the consumers to choose. The solar panel is on the outer surface to maximize the solar energy absorption, as well as its transforming into electrical energy storage. In addition, this washing machine is a home appliance product supported by Internet to Things technology. Manufacturers provide APP software application for users to download on their smart mobile terminals. Therefore this intelligentize design reduces the hardware cost as for remote-controller.

\section{Conclusion}

Design is a re-recognition and re-creation of artificial 
objects. The key point of this scientific research is to shift the perspective of industrial design from the focus on things to the concern for relationships between things and people's behavior. Due to the specific environmental factors, human factors, habits, and cognition of the washing machine users in the secondary and tertiary markets, the external appearance, human-computer interaction, and concept trends must be different during design process. Some of the design elements proposed this time have been effectively applied in the actual product designs, and well approved by relevant developers in the company. I hope these design elements can provide references to the washing machine design improvement in the mid-and-low-end market.

\section{Acknowledgment}

Funded Program. Young teacher research fund project of Sichuan University Jinjiang College.

Item number: 12110106

\section{References}

1. Li Binbin. Design Psychology. Beijing: China Light Industry Press, ( 2009)
2. Xiong Xiqiu, Jiang Wenping. Research on Design of Smart Home Control Panel Based on Interactive Experience. [J] Mechanical Design, (2014)

3. Liu Jingyu. Conceptual Analysis of Product Appearance Design. M D, 02(2013).

4. Yu Dongjiu, Feng Yajuan. Consumer-oriented Product Design Research [J] Mechanical design and manufacturing, (2007)

5. Mo Lian. Research on Product Design Method Based on Life Style. [J] Mechanical Design, (2013)

6. Lin Liang. Analysis of ergonomic application points in product modeling design, V E,36(2015) .

7. Yu Wenjun, Ling Zhihao. Research on the Internet of Things Smart Home System . [J] Automated Instrument.(2011)

8. Huang Sheng, Zhang Linghao. Research on VUX System Design Based on the Users' Visual Experience of Drum Washing Machines' Hard Interface, Chongqing: Packaging Engineering, (2015)

9. Plummer Jospeh T.The concept and application of lifestyle segmentation [J]Journal of Marketing, (1974) 